\title{
Seasonal sea-level predictions for the Western Pacific
}

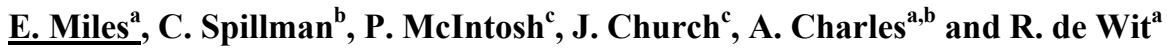 \\ ${ }^{a}$ National Climate Centre, Bureau of Meteorology, AUSTRALIA \\ ${ }^{b}$ Centre for Australian Weather and Climate Research (CAWCR), Bureau of Meteorology, AUSTRALIA \\ ${ }^{c}$ CSIRO Wealth from Oceans National Flagship, AUSTRALIA \\ Email: e.miles@bom.gov.au
}

\begin{abstract}
Seasonal forecasting from dynamical ocean-atmosphere models of sea-level anomalies (SLA) has great potential for coastal communities in the Western Pacific, allowing the implementation of management policies and strategies to minimise loss of life and infrastructure damage. In recognising that it is through natural variability that the early effects of climate change are most acutely felt, the PacificAustralia Climate Change Science Adaptation Planning Program (PACCSAP) seeks to assess the relationships between the seasonal variability, regional sea-level and its predictability at a seasonal timescale.

Real-time forecasts for SLA in the Western Pacific are currently produced operationally using the Bureau of Meteorology's seasonal forecast model POAMA. This work represents the first attempt to predict seasonal SLA up to 7 months into the future using a coupled dynamical model. These forecasts provide an early warning of potential extreme sea-level, which allows coastal managers to both minimise coastal damage and ensure water security, as well as brief stakeholders. Additionally, probabilistic forecasts provide information as to the likelihood of an extreme seasonal mean state, which is very useful for management in planning responses and focusing resources.
\end{abstract}

An online portal has been created to deliver the seasonal forecasts and accompanying skill scores. Website development was done in consultation with regional stakeholders with the aim to produce useful and easily understood seasonal forecasts. These forecasts are a new product for regional stakeholders and the assessment of the forecast usefulness and application is an ongoing task. As global warming is likely to increase the frequency and severity of extreme SLA events the development of such forecast products is crucial to combat problems due to climate change in the near future.

Keywords: $\quad$ Sea-level, dynamic modeling, Pacific-Australia Climate Change Science Adaptation Planning Program (PACCSAP), seasonal forecasting, POAMA 


\section{INTRODUCTION}

Climate change is an increasing concern for communities in the Western Pacific region. The Intergovernmental Panel on Climate Change (IPCC) identified sea-level rise and the associated extreme sealevel events to be one of the most profound impacts resulting from climate change, causing enormous damage to infrastructure, social and economic stress, and, in extreme cases, loss of life. Accurate predictions of seasonal sea-level enable communities to prepare for extreme events. Currently predictions of the diurnal tide and its seasonal variation are made routinely to high accuracy, storm surges can be predicted out to almost two weeks using a weather model coupled to a regional high resolution ocean model, and sea-level rise due to climate change, which represents only a small component of a prediction on seasonal timescales, is well modeled. However, the contributions to seasonal sea-level due to climate processes such as ENSO, the IOD, the MJO and the SAM are not currently modeled. This is despite these processes involving large time- and space-scale changes to winds and ocean temperatures, which in turn can affect regional sea-level. These sea-level changes can last for many months and have significant amplitudes. When combined with sealevel increases from spring tides and/or storm surges, these seasonal sea-level processes have the potential to exacerbate an already damaging situation. Thus, creating dynamical seasonal sea-level anomaly forecasts will contribute to closing the current gap in predicting all of the major components influencing regional sea-level.

The International Climate Change Adaptation Initiative (ICCAI) - an Australian Government initiative to address high priority climate adaptation needs in vulnerable countries in the Asia-Pacific region - recognises that seasonal and inter-annual climate variability is a major factor in determining the vulnerability of countries to climate change given the interaction between climate variability and the changing background climate which alters the character of sea-level events. Under the ICCAI-funded PACCSAP (Pacific Australia Climate Change Science and Adaptation Planning) program, work has been undertaken with Western Pacific countries both north and south of the equator to deliver improved seasonal forecasting technologies and capacity. The countries involved are Timor Leste and 14 Pacific Island Nations: Papua New Guinea, Tuvalu, Kiribati, Fiji, Marshall Islands, Federated States of Micronesia, Palau, Nauru, Cook Islands, Samoa, Tonga, Niue, Solomon Islands, and Vanuatu (subsequently referred to as the "Partner Countries").

This paper describes the scope for seasonal SLA forecasts created by POAMA (Predictive Ocean Atmosphere Model for Australia), a global coupled ocean-atmosphere ensemble seasonal prediction system, to play an important role in coastal communities managing climate change. A prototype online portal for delivering these predictions has been launched. Along with seasonal SLA and probabilistic predictions, the portal also delivers the skill of the forecasts based on analysis of hind-casts. This paper describes the dynamical coupled model used to create these seasonal predictions, the seasonal forecast products, the web portal and the use and applicability of the predictions in coastal management.

\section{SEASONAL FORECASTING}

Two methods can be used to create predictions several seasons into the future: statistical and dynamical models. Statistical models create forecasts based on observed historical lagged relationships. Whilst statistical models often have good skill, they are surpassed by dynamical models when there are unprecedented changes to physical forcings, such as under climate change. Dynamical models determine the future state by solving numerically the physical and fluid-dynamical equations describing the ocean and atmosphere. These models can be very complex systems, requiring a detailed understanding of the processes involved, as well as computationally demanding but, being multivariate in nature, can simulate system responses to a changing climate.

Seasonal predictions provide information on the likelihood of extreme events to stakeholders, giving them time to design and implement strategies to minimise impacts. Designing products for stakeholders requires consideration of many factors. It is important to develop a good understanding of who the end user will be, what resources they have access to and what kind of forecast products they want. Other aspects are: establishing the format of the predictions (e.g. spatial grids, line graphs), determining the useful timescale for management to respond, and deciding what level of certainty is required for responsive action. In addition to the portal design, it is important to educate end users on the strengths and weaknesses of forecast products and the best way in which to interrogate the predictions. Thus online delivery of forecasts can be the most effective method of product dissemination though this needs to be combined with appropriate training.

\section{MODEL DETAILS}

POAMA is a global coupled ocean-atmosphere ensemble seasonal prediction system developed jointly by the Australian Bureau of Meteorology and the Commonwealth Scientific and Industrial Research 
Organisation (CSIRO) Division of Marine and Atmospheric Research (CMAR) (Hudson et al., 2013). POAMA produces intraseasonal-to-seasonal predictions of the global climate (ENSO indices, rainfall and ocean temperature forecasts) and has been running operationally at the Bureau of Meteorology since 2002.

POAMA (multi-week version 2.4) consists of a coupled ocean-atmosphere model and a data assimilation system for the initialisation of the ocean, land and atmosphere and produces an ensemble of 33 members. A major advancement in this version of POAMA is the generation of ocean initial conditions through a new state-of-the-art, ensemble-based ocean data assimilation scheme called the POAMA Ensemble Ocean Data Assimilation System, (PEODAS, Yin et al. 2011) and enhanced initialisation and ensemble generation schemes (Hudson et al., 2013).

The ocean model used by both POAMA and PEODAS, the CMAR Australian Community Ocean Model version 2 (ACOM2; Schiller et al. 2002), is based on GFDL's Modular Ocean Model version2 (MOM2, Pacanowski 1996) and does not explicitly represent sea-level. Instead it returns a model diagnostic variable described as the "diagnostic surface height" and referred to as sea surface height (SSH). ACOM2 uses a rigid-lid approximation which conserves volume (Bryan 1969), and the surface height variations for each grid cell are determined by using the hydrostatic equations to calculate the perpendicular forcing to this surface generated by water being shifted into different grid columns due to horizontal temperature, salinity and wind gradients. This calculation reflects the contributions to sea-level from dynamic height, barotropic circulation, advection and dissipation processes. The following contributors to sea-level variations are not simulated: changes in ocean mass from ice-sheet mass loss or other contributions, tectonic uplift, selfattraction and loading, glacial isostatic adjustment (GIA), land water storage, astronomical tides, surface waves, mesoscale eddies or atmospheric pressure effects within the ocean model.

By investigating the variability of the ensemble forecasts for a given forecast issue date it is possible to estimate the spread or uncertainty in the future evolution of the climate system. The skill of the system is determined by comparing POAMA hindcasts against the PEODAS reanalyses. The hindcast dataset extends from 1981-2010 and is initialised at the start of every month. Real-time forecasts of the 3-month average sealevel condition are now created twice a week.

\section{SEA-LEVEL FORECAST PRODUCTS}

POAMA is used to create the entire suite of PACCSAP sea-level forecast products. SLA values are calculated as the difference between SSH values and the relevant climatology. Monthly SSH climatologies for 1981-2010 are computed relative to the start month and lead-time and subtracted from the individual forecasts to correct for any model bias (Stockdale 1997). Lead-time is defined as the time elapsed between the model start date and the forecast date, i.e. if the model start date is 1 January, for forecasts for January, February, March and April the lead is 0, 1, 2 and 3 months, respectively. Generally, forecast accuracy is highest for lead-time 0 months and decays as forecasts predict further into the future (i.e. increasing leadtime). The model ensemble members are then averaged to create the ensemble mean. To calculate a three monthly (average) seasonal forecast, the monthly forecasts are averaged according to lead-time. For example, the forecast for the January, February and March (JFM) season at lead-time 0 months is the average of January, February and March for the forecasts starting 1 January. For a JFM forecast at a lead-time of 1 month, January, February and March are averaged for forecasts starting on 1 December.

To evaluate the accuracy of model forecasts and provide a measure of the skill of the model, SLA hindcasts are compared to a SLA reanalysis generated by PEODAS. Assessment of model performance or skill is determined at each grid point for a target season through the calculation of metrics such as correlations (e.g. Figure 1) and RMSE for deterministic forecasts, and accuracy and relative operating characteristic (ROC) score for probabilistic forecasts. The ROC score is a measure of a model's ability to discriminate between events and non-events (i.e. do forecasts of a high event probability tend to be followed by events?) and can be considered as a measure of potential usefulness (Jolliffe 2012). The desired level of forecast skill is dependent on the application and there is often lower accuracy in predicting local scale events compared to large climate processes (McIntosh et al. 2013). Further studies into how POAMA performs globally and its ability to model SLA variability (Miles et al. 2013) as well as comparisons with performance in the Western Pacific relative to tide gauge observations and statistical models (McIntosh et al. 2013) have been conducted. These studies demonstrate POAMA high skill (beating persistence) at lead-times out to 6 months in the low latitude Pacific and to a lesser extent Indian Oceans. The results are accessible on the website alongside the forecasts. 




Figure 1 POAMA anomaly correlations for forecasts targeting the seasons January-February-March (JFM), April-May-Jun (AMJ), July-August-September (JAS) and October-November-December (OND) for lead times 0, 3 and 6 months in advance. Black lines indicate Exclusive Economic Zones (EEZ) of Partner Countries.

\section{WEBSITE DELIVERY}

Currently seasonal forecasts of SLA are available within the PACCSAP portal and are updated twice a week every Monday and Thursday at 00Z. The website delivers gridded deterministic and probabilistic forecasts out to 6 months lead time. Table 1 provides details on these forecasts and the calculated skill scores. Figure 2 shows examples from the web portal of deterministic and probabilistic SLA forecasts for October to December 2013, issued 1st July 2013.

Table 1 Details of the mapped seasonal SLA forecast products.

\begin{tabular}{|c|c|c|c|}
\hline Quantity & Units & Description & Skill scores available \\
\hline SLA & $\mathrm{cm}$ & Seasonal mean sea-level anomaly from 1981-2010 climatology & Correlation, RMSE \\
\hline Upper Tercile & Percentage & $\begin{array}{l}\text { Percentage of ensemble members in upper tercile using 1981-2010 } \\
\text { climatology }\end{array}$ & Accuracy, ROC \\
\hline Lower Tercile & Percentage & $\begin{array}{l}\text { Percentage of ensemble members in lower tercile using 1981-2010 } \\
\text { climatology }\end{array}$ & Accuracy, ROC \\
\hline Composite Tercile Map & Percentage & $\begin{array}{l}\text { Sea-level Anomaly Tercile Probabilities } \\
\text { 'Ind' forecasts show grid points where all tercile states have a } \\
\text { probability of less than } 40 \% \text {. } \\
\text { 'Amb' forecasts show grid points where two terciles have the same } \\
\text { probability of occurring }\end{array}$ & N/A \\
\hline
\end{tabular}




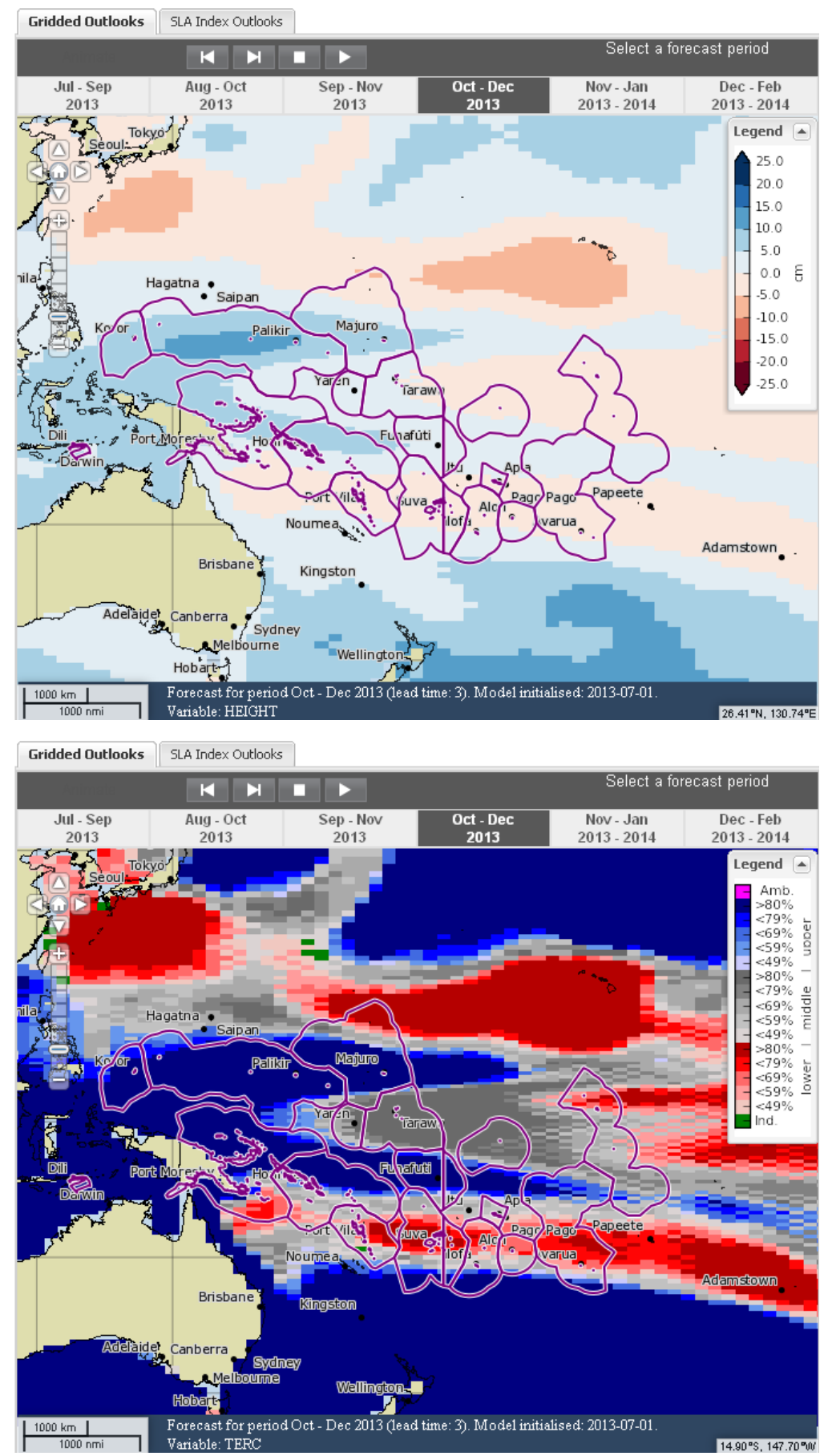

Figure 2 Example of an SLA forecast for October to December 2013, issued 1st July 2013 (based on 33 monthly ensembles): POAMA ensemble mean forecast of monthly SLA based on the ensemble mean (top) and probability of terciles events (bottom) (available from http://poama.bom.gov.au/experimental/pasap/sla.shtml).

Plume plot forecasts for the exclusive economic zone (EEZ) of each Partner Country are also available on the web portal. These forecasts are created by calculating the average SLA value within the EEZ for each of the 33 ensemble members. RMSE and correlation values are calculated for the ensemble mean. Figure 3 shows an example of a plume plot and relevant RMSE and correlation scores for the Federated States of Micronesia for October to December 2013, issued 1st July 2013. 
E. Miles et al., Seasonal Sea-level predictions for the Western Pacific

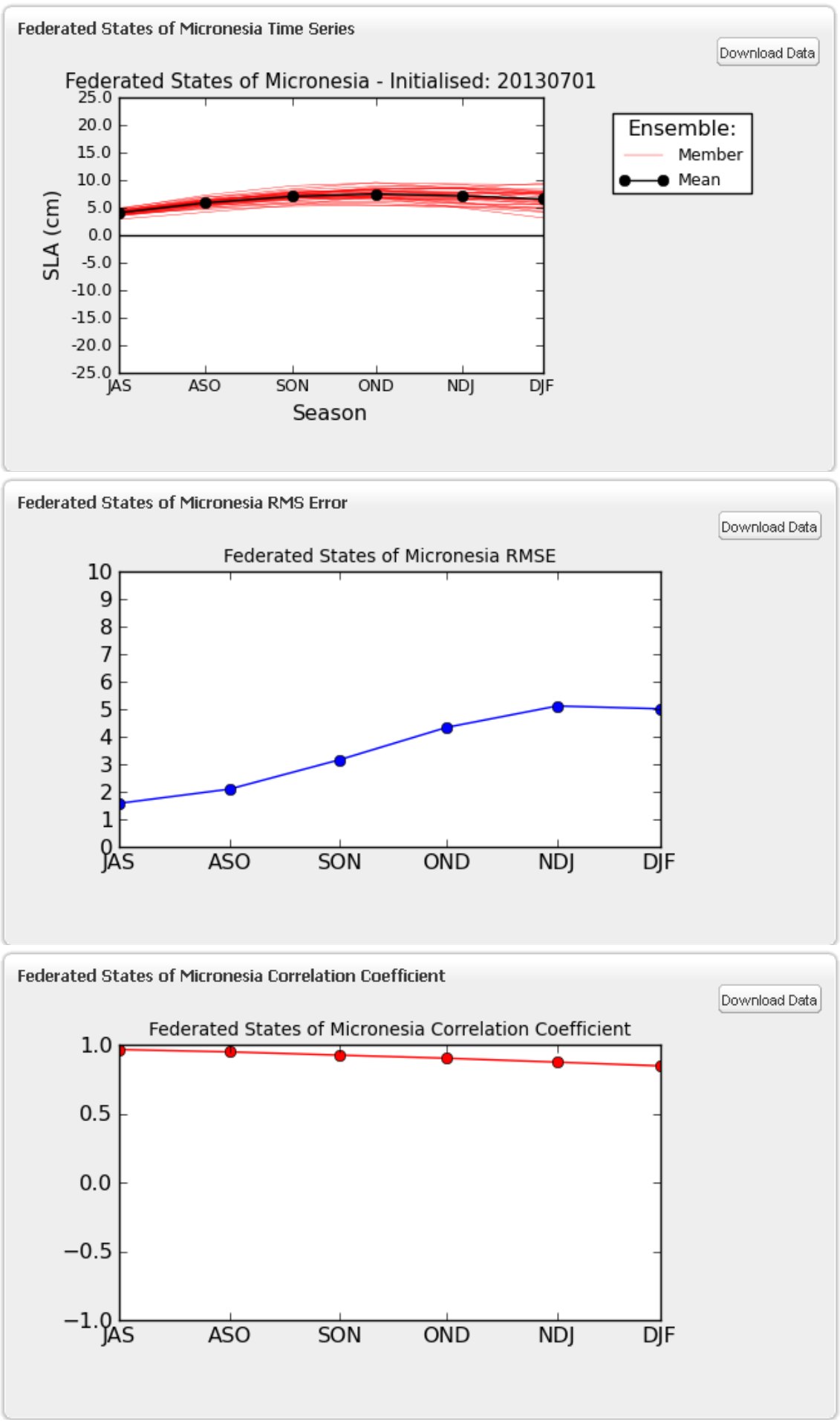

Figure 3 Example of an SLA plume plot forecast for the Federated States of Micronesia from July 2013 to February 2014, issued 1st July 2013 based on 33 monthly ensembles (top) and the corresponding RMSE (middle) and correlation (bottom) skill plots (available from http://poama.bom.gov.au/experimental/pasap/sla.shtml).

\section{USE OF FORECASTS BY MANAGEMENT}

Use of seasonal sea-level forecasts is a new development for Partner Countries in the PACCSAP project. Forecasts can be used to inform stakeholders and to assist in preparing management decisions and communities for extreme events and protecting infrastructure. Seasonal forecasts have already been demonstrated as a valuable tool in reef, fishery and agriculture management, allowing for proactive 
management responses and the early implementation of preventative measures. Some examples of POAMA seasonal forecasts being used currently include the Great Barrier Reef Marine Park Authority Coral Bleaching Response Plan (Maynard et al. 2009) where POAMA is an important component of the Early Warning System strategic framework, the management of dual purpose farms based on seasonal forecasts (Asseng et al. 2012), and the regulation of access to tuna habitats in Australia by Australian Fisheries Management Authority (Hobday et al. 2011).

Currently seasonal forecasts for rainfall and temperature are being utilised by Partner Countries (Cottrill et al. 2013). More work is needed to improve the understanding of how SLA forecasts are used by stakeholders in Partner Countries, and if stakeholder decisions are influenced by the SLA forecasts. So far very positive feedback has been received from Partner Countries about seasonal SLA forecasts e.g. at the PACCSAP science symposium and workshop conducted in Honiara, Solomon Islands 2013.

\section{CONCLUSIONS AND RECOMMENDATIONS}

Seasonal forecasts of SLA generated by POAMA are a valuable tool for proactive coastal management. There are a number of Partner Countries in the Western Pacific that are currently using, or interested in using, seasonal forecast products in their management plans to increase resilience to the adverse impacts on their communities and infrastructure of rising sea-levels. Education in the use of these tools is very important so that stakeholders can understand both the strengths and limitations of forecast products and the best way to interpret forecasts. Adoption of products over a period of time is more likely to result in long term benefit than adoption for a single season. Probabilistic forecasts are important for management in terms of analysing the risk or cost/benefit of implementing a particular strategy such as monitoring mid-range and short-term forecasts closely, updating contingency plans and educating communities.

\section{ACKNOWLEDGMENTS}

This research contributes to the Pacific Australia Climate Change Science and Adaptation Program (PACCSAP) funded by AusAID and the Department of Climate Change and Energy Efficiency and delivered by the Bureau of Meteorology and CSIRO. We thank Kay Shelton and Aurel Griesser for reviewing this paper, Griffith Young, Guomin Wang and Faina Tseitkin for hindcast preparation, Yonghong Yin for the PEODAS reanalyses and Neil White for the analysis of observed sea-level.

\section{REFERENCES}

Asseng S, Thomas D, McIntosh P, et al. (2012) Managing mixed wheat-sheep farms with a seasonal forecast. Agricultural Systems 113:50-56.

Bryan K (1969) A Numerical Method for the Stu of the Circulation of the World Ocean. Journal of Computational Physics 4:347-376.

Cottrill A, Hendon H., Lim E-P, et al. (2013) Seasonal Forecasting in the Pacific using the coupled model POAMA-2. Weather and Forecasting 28:668-680.

Hobday AJ, Hartog JR, Spillman CM, Alves O (2011) Seasonal forecasting of tuna habitat for dynamic spatial management. Canadian Journal of Fisheries and Aquatic Sciences 68:898-911.

Hudson D, Marshall AG, Yin Y, et al. (2013) Improving intraseasonal prediction with a new ensemble generation strategy. Monthly Weather Review

Jolliffe IT and Stephenson DB (2012) Forecast Verification: A Practitioner's Guide in Atmospheric Science. 2nd Edition. Wiley and Sons Ltd, $274 \mathrm{pp}$.

Maynard JA, Johnson JE, Marshall PA, et al. (2009) A strategic framework for responding to coral bleaching events in a changing climate. Environmental Management, 44:1-11.

McIntosh PC, Church JA, Miles E, et al. (2013) Seasonal Prediction of Western Pacific Sea-level using a Coupled Ocean-Atmosphere Dynamical Model. In prep.

Miles E, Spillman CM, Church JA, Mcintosh PC (2013) Seasonal Prediction of Global Sea-Level Anomalies using an Ocean-Atmosphere Dynamical Model. Submitted to Climate Dynamics.

Pacanowski RC (1996) MOM2: Documentation, User's Guide and Reference Manual.

Schiller A, Godfrey JS, McIntosh PC, et al. (2002) A New Version of the Australian Community Ocean Model for Seasonal Climate Prediction. doi: 551.630994

Stockdale TN (1997) Coupled Ocean - Atmosphere Forecasts in the Presence of Climate Drift. Monthly Weather Review 125:809-818.

Yin Y, Alves O, Oke PR (2011) An Ensemble Ocean Data Assimilation System for Seasonal Prediction. Monthly Weather Review 139:786-808. doi: 10.1175/2010MWR3419.1 